\title{
A Study of the Effect of Network-based English Teaching on College Students' Creative Thinking Ability and Creative Attitude
}

\section{Zhou Ting}

\author{
Wuhan Polytechnic University
}

Abstract - Creativity is a key element in the construction and development of a nation. The essential goal of quality-oriented education is to improve the quality of all college students, which focuses on cultivating their creative spirit and the ability to experiment. English education is an important component of college education. But for many years, English teaching in our country has been far from satisfaction. This article investigated and studied the effect of network-based English teaching on college students' creative thinking ability and attitude by comparing the results of college students' creative thinking ability and creative attitude under network-based English teaching circumstances and under traditional English teaching circumstances, based on network-based language teaching and creativity thinking theories. Besides, the differences between female and male students in their creative thinking ability and creative attitude were explored. The results of the study showed that network-based English teaching exerts some effects on improving college students' creative thinking ability, that students' creative attitude can be improved more or less under network-based English teaching circumstances comparing with under traditional English teaching circumstances, and that female students' creative thinking ability and creative attitude is relatively higher than males'. This article also made some suggestions on how to nurture student's creative thinking ability under network-based English teaching circumstances.
Key words- network-based English teaching creative thinking ability creative attitude

\section{Introduction}

Throughout history, great thinkers have used their creativity and imagination to change the world. Creativity is a key element in the construction and development of a nation. General Secretary Jiang Zemin has pointed out that education undertakes a special mission in cultivating the whole nation's creative spirit and creative talents (Yao, 2002). Those educational notions and modes that hinder the development of creative spirit and ability of students must be changed, especially those of merely teaching of knowledge by teachers, taking test score as the only standard of judging students (Zhang, 2003). In 1982, American English Teachers' Association pointed out that "In order to improve language ability, thinking skills must be developed; stimulation of thinking must be instructed by English teachers. In the national education conference of 1999, it was further made clear that the essential goal of quality-oriented education is to improve the quality of all the people, which focuses on cultivating the students' creative spirit and the ability to do experiments, calling for taking into consideration of physical and psychological features of students, so as to enable students to develop themselves lively, vigorously, and actively (Tian, 2001). In 2000, The English Teaching Syllabus for English Majors, 
published by the Educational Department of China, stated that teaching had been always emphasizing the training of students' capability of imitating and memorizing knowledge from textbooks, while neglecting cultivating students' thinking ability, problem-analyzing ability and apperceiving ability, thus resulting in a lack of learning autonomy and originality (He, 1999). Also in 2000, nurturing students' creative thinking ability should be one of the most important tasks for English teachers. (Guo, 2005)

This paper, therefore, attempts to investigate and study the effect of network-based English teaching on college students' creative thinking ability and attitude, based on network-based language teaching and creativity thinking theories, by setting up two research questions: 1) Whether will college students' creative thinking ability and creative attitude change under network-based English teaching circumstances? 2) Whether will college students' creative thinking ability and creative attitude change according to sex? It is hoped that the findings of the study will be of some help to promote students' creative thinking ability, and thus contribute more or less to English teaching in China.

\section{Literature Review}

\subsection{Network-based language teaching}

\subsubsection{The characteristic of NBLT}

Network-based Language Teaching (NBLT) is language teaching that involves the use of computers connected to one another in either local or global networks. (Mark Warschauer, Richard Kern, 2000). Warschauer and Kern (2000) also claim that in a network-based language teaching (NBLT) environment, learners can "access and/or publish texts and multimedia materials and extend their communicative experience to worlds far beyond the classroom". NBLT is, as such, a branch of CALL, where human-to-human communication is the main focus. NBLT incorporates language teaching through all kinds of CMC, as well as through web-based activities.

Network-based Language Teaching is a new teaching model of utilizing web resources in English teaching. Based on the application of multimedia, supplied by school net and the Internet, NBLT mixes the new information technology (such as the computer and web) with English teaching. NBLT has the following characteristics:

* Openness. Net is a huge resource pool. Comparing with the printed textbooks, it possesses openness in that resources are dynamic and renewable with the latest and popular learning materials; resources are various covering nearly every aspect of the society, which provides many choices for students to cultivate their autonomous learning ability and resources are vivid with pictures and sounds, which can easily catch students' attention and arouse their interest.

\subsubsection{Changing nature of computer use in language teaching}

It is within the shifting context of structural, cognitive, and sociocognitive orientations that we can understand changes in how computers have been used in language teaching, and in particular what role network-based language teaching has today. Interestingly, shifts in perspectives on language learning and teaching have paralleled developments in technology from the mainframe to the networked computer (Warschauer \& Kern, 2000). The introduction of a new phase in CALL does not necessarily entail a rejection of the programs and methods of the previous phase. More often, the old is often included in the new. In addition, new phases do not gain prominence over night. Like 
most innovations, they win acceptance slowly and unevenly (Warschauer, 1996a).

The earliest CALL programs, consisting of grammar and vocabulary tutorials, drill and practice programs, and language testing instruments, strictly follow the computer-as-tutor model. Developed originally for mainframe computers in the 1960s and 1970 s, though still used with different variations today, these programs are designed to provide immediate positive feedbacks to learners on the formal accuracy of their responses. This is consistent with the structuralist approach, which emphasizes that repeated drilling on the same material is beneficial or even essential to learning (Kern \& Warschauer, 2000). Language teaching from a structural perspective emphasizes the formal analysis of the system of structures that make up a given language. From the $1920 \mathrm{~s}$ through the $1950 \mathrm{~s}$ various other structural methods of language instruction were developed, culminating in the audio-lingual method of the 1940s and 1950s (Kern \& Warschauer, 2000). The audio-lingual method focuses on spoken rather than written language skills, based on the theory that speaking and listening competence precedes competence reading and writing. The method is built on behaviorist principles of conditioned responses. Language learning is seen as a habit formation. Students should practice particular patterns of language through structured dialogues and drills until the language is sufficiently rehearsed for responses to be automatic (Kitao \& Kitao, 1996). The rationale behind the drill and practice programs is as follows:

*Repeated exposure to the same material is beneficial or even essential to learning

*A computer is ideal for carrying out repeated drills, since the machine does not get bored with presenting the same material and since it can provide an immediate non-judgmental feedback *A computer can present materials on an individualized basis, allowing students to proceed at their own pace and freeing up class time for other activities (Warschauer, 1996a)

However, drill programs of this kind generate little excitement among learners and teachers, since they only represent perpetuated existing instructional practices, although in a new form. These programs also tend to be technically unsophisticated, generally allowing only one acceptable response per item. These factors, combined with the rejection of purely behaviorist approaches to language learning, and the development of more sophisticated personal computers, set the stage for a new phase of CALL (Kern \& Warschauer, 2000).

This may seem to leave CALL somewhat in a vacuum, since the technological development cannot keep up with the theoretical one. Fortunately, this is not the case. The technical development has merely gone in a different direction from what was perhaps expected ten years ago. The advent of the Internet and the network has given language teachers ample opportunities to realize a sociocognitive approach to CALL. The networked computer provides the opportunity to meet the criteria of a sociocognitive approach to language learning by shifting from learners' interaction with computers to interaction with other human beings via the computer. The computer no longer functions as a tutor, but as a tool giving learners an access to all sorts of authentic language material and to other learners, or native speakers, of the language.

\subsection{Creative thinking ability}

\subsubsection{Creativity}

What is creativity? Creativity has been defined in a number of different contexts. It is 
generally considered to be the ability which leads to a new idea or a fresh insight, and to be the ability to break from rigid habits, that defeat of habit by originality. In Longman Modern English Dictionary (Page253), creativity is defined as "being a process which produces something, which not naturally evolves or which is not made by ordinary means". Boden (2001: 95) believes that creativity is 'the ability to come up with new ideas that are surprising yet intelligible, and also valuable in some way.' Ausubel (1963) defines creativity as 'a rare and unique talent in a particular field of endeavour', whilst Bruner (1962) offers a less elitist definition when he suggests that creativity results in 'an act that produces effective surprise'. Creativity is evident in a number of diverse learning contexts. Lucas, for example, sees creativity as a cognitive process in which all of our intelligences are working in harmony, and specifically where seeing, thinking and innovating are combined (Gardner, 1983; 1999). For the purpose of research on creative thinking, creativity is often considered to consist of two elements: fluency and flexibility. Fluency is evidenced by the ability to smoothly and rapidly produce a large number of solution ideas for a problem. Flexibility generally refers to the capability of finding divergent, unusual solution ideas for a problem. Flexible thinking is also evidenced by the ability to find divergent uses for existing products.

\subsubsection{Creative thinking ability}

To develop the potential for creation, it is important to learn to think creatively. Creative thinking refers to the process of modifying ideas, from an existing knowledge base, with the ability to form or bring forth a new thought by using imagination and intellect. It's a part of an individual's intellectual personality that can be applied to everyday situations. Creative thinking is built around three human thought processing functions (John. F, 1995):

Referring to the above definitions, a working definition of creative thinking ability is presented as follows: creative thinking ability involves originality - producing unique, unusual, or novel responses, relative to one's reference group, fluency - thinking or producing ideas or responses quickly, flexibility-producing a variety of ideas or using a variety of approaches, and elaboration - thinking or filling the need in detail and implementing it. Therefore, these four characteristics of students' creative thinking ability are mainly researched in my paper.

\subsubsection{The relationship between language and creative thinking ability}

Linguistic Competence and communicative competence are two aspects of language learning, and their improvement can not be separated from thinking. Thinking and language are interrelated, and thinking ability, especially creative thinking ability is the key to promoting linguistic competence (Fan, 2004). Psycholinguists point out that thinking is the product of human brain and the brain's reflection activity of materials' characters and relationship, and it exists through language. Language is the tool of thinking. Thinking can be functioned on language, no matter it is a foreign language or the mother tongue (Jia, 1999).

Therefore, in teaching English, teachers should train students' creative thinking ability by combining textbooks and real-life tasks to well nurture students' thinking ability, problem-solving ability and knowledgereorganizing ability.

\subsection{Creative attitude}

Creative attitude is an important component 
of creativity. Creative attitude is an individual's cognitive, emotional and behavioral tendency towards innovative things, ideas and activities. In Encyclopedia, Davis (1995) describes the characteristics of creative attitude as awareness, originality, adventure, curiosity, imagination, impulsion, immaturity, caprice, etc. From research results of Schaefer, C.E (1971), we can find that one's creative attitude relates with confidence in one's own ideas, appreciation of fantasy, theoretical and aesthetic orientation, openness to impulse expression, and desire for novelty.

\subsection{Previous studies}

Over decades, there have been many researches on cultivating college students' creative thinking ability by teaching in our country, covering education of mathematics, chemistry, physics, politics, Chinese and English as well For instance, Luo Xinbing analyses the restricted elements of training creating thought in mathematics teaching (Luo, 2004). Wang Zhaohong innovates the teaching of physics in high schools and finds out that it is effective to foster the creative thinking ability in teaching physics (Wang, 1999). Qian Aijuan studies the problem of how to cultivate the students' creative ability of thinking in teaching politics in senior middle school (Qian, 2001). In English, Li Jiazeng, etc (1995) evaluate the characteristics of creative thinking of university students. Years later, Li Jiazeng, etc conduct a research on the characteristics of students' creative thinking and their relations to creativity in aspects of fluency, flexibility and elaboration, based on the results of creative thinking tests at Southeast University. They stress that it is important to train fluency and flexibility of thinking in order to develop students' creative thinking ability. They also state the reform in the education, including setting up a course of creativity development for students and improving teaching methods in class is of the utmost importance (Wen \& Song, 1999). In the research done by Zeng Lisha, it is found that it is helpful to foster students' creative thinking by asking them to try in class translating one sentence into different versions, using different tenses (Zeng, 2000). Gao Lin (2002) focuses her study on how to develop creative thinking, how to maintain the relationship between developing English language skills and thinking, and how to realize creativity-led English teaching.

Besides, many researches can also be found on computer-assisted language learning both at home and abroad, since the computers can handle a wide range of activities, and offer some interactive learning. Computers are more available for creative and imaginative teaching by handling different kinds of material. Quite few researches, however, have been undertaken on the promotion of creative thinking by Network-based English teaching.

\section{Methodology}

\subsection{Subjects}

The subjects of the study are freshmen chosen from Wuhan Polytechnic university .136 students, from different majors, in Class 1 and Class 2 participate in the investigation. Class 1 is experimental class and Class 2, control class. There are 43 male students and 25 female students in experimental class and 48 male students and 20 female students in control class. Subjects chosen are freshmen. They have just finished their high school, which adopts an exam-oriented education while neglects cultivating students' creative thinking ability, and begun college education. Therefore, subjects of the experiment are suitable and typical. Meanwhile, students in class 1 and class 
2 are both instructed by the author.

\subsection{Study instruments}

Two tests, Diagnoses Table on Creative Thinking Ability, edited by Zheng Richang, Test on Creative Attitude, edited by Qian Gaoyuan, which have been adopted by many researchers in different fields are used in this study. Two tests include the basic information (gender and age) about students, and they are conducted to attempt to compare the results of creative thinking ability and creative attitude between experimental class and control class and to explore the differences in creative thinking ability and creative attitude between male and female students. Diagnoses Table on Creative Thinking Ability has twenty questions, which reflects originality, fluency, flexibility and elaboration of creative thinking ability. The subjects are required to finish them independently and anonymously. Test on Creative Attitude has forty-five items. The subjects are required to choose one from five options, which vary from "A strongly agree", "B agree", "C not sure", "D disagree" to "E strongly disagree" for each item. Since some students' English is not very good, two tests are given in Chinese to avoid misunderstanding and to ensure the fluent on-going of this survey.

\subsection{Description of teaching experiment}

The experiment in experimental class lasts for 13 weeks. Each week, they have 4 classes focusing on the training of their creative thinking ability (using Experiencing English Integrated textbooks).Both in class and after class, students are instructed to finish the learning tasks by using the Internet. Specifically, in class, they have to go online to participate in interactive activities by collaborating with other students. After class, they are asked to spend at least four hours each week doing the assigned work of reading and writing, which needs a lot of creation and imagination. To be exact, during the experiment, in experimental class, network-based English teaching method is adopted by making use of some self-made teaching materials downloaded from the internet. Besides, loads of homework is assigned to students requiring a search of information online each week by going into the websites which are provided by the instructor, such as http://www.globalenglish.com

http://www.englishtown.com, http:// www. teachingenglish.org.uk/ http://www.studioclassroom.com , and http:/ lwww. bbc.co.uk Mearning Mibrary/english_language.shtml, etc. A feedback of students' work is given, too. In control class, a traditional teaching method is employed on students with no web resources provided and with textbooks as the learning material only.

\subsection{Data collection}

Two tests are conducted respectively at the beginning and at the end of the term, with the time limit of 30 minutes for each. Altogether 123 pieces of two tests paper are distributed to students of two classes.123 copies are finally returned and 120 of them are found to be valid.

\subsection{Data analysis}

The data are analyzed statistically in three major ways: results of the questionnaire presented in percentage, results of two tests shown through a paired sample test and results of two tests shown through a group statistics comparison. Test on Creative Attitude used a Likert Scale with choices A, B, C, D and E. Each has a certain value of 5 points, 4 points, 3 points, 2 points and 1 point respectively. The more value s/he get, the higher level of his/her 
attitude is. The results are then typed into the computer with the software SPSS11.5 for analysis. For Diagnoses Table on Creative Thinking Ability, each question has its own defined score, varying from 1 to 6 points. Students' answers are checked, and the final scores are calculated. The higher the final score, the stronger ability the subjects acquire.

In item ST13, the statement is that "In senior school, does your English teacher use computers in teaching?" $67.6 \%$ of the students choose A which stands for "never". 25.7\% choose B for "sometimes", and $6.7 \%$ choose C for "often".

In item ST14, the statement is that "In senior school, do you take any English tests online?" Most of the students (84.9\%) take no English tests online, while some students (15.1\%) sometimes do. And none of the students often take tests online.

In summary, from the results analysis above,

Table4.1 and Table4.2 are the comparisons of group statistics of the pretest and posttest in creative thinking ability between control class and experimental class. In group statistics of Table4.1, we could find that the males' means of the control class in the creative thinking ability pretest is 45.9535 , which is lower than females' means of the control class: 59.0000; the males' std. deviation is 11.68221, the females' std. deviation is 11.02724 , the males' std. error mean is 1.78152, the females' std. error is 2.40634. The males' means of the experimental class in the creative thinking ability pretest is 51.4359 , which is lower than females' means of the experimental class: 58.1389. The males' std. deviation is 13.58171; the females' std. deviation is 11.19733. The

\section{Findings and Discussion}

\subsection{The general situation of students' Internet application}

The general situation of students' application of internet is investigated among students in experimental class. Table 4.0 is a description of students' internet application

it is quite possible for students to receive learning online since they have an access to computers, and they have some idea about the internet, and they use computers before more or less.

\subsection{Comparisons of results of creative thinking ability between male and female students}

In this experiment, both male and female students receive the same creative thinking ability tests twice. Below are tables of group statistics in control class and experimental class.

males' std. error mean is 2.17481 ; the females' std. error is 1.86622. Through the group statistics in pretest, it can be found that males' creative thinking ability is lower than females'. In group statistics of Table4.2, it shows that the males' means of the control class in the creative thinking ability posttest is 46.8500 , which is lower than females' means of the control class: 60.0476. The males' std. deviation is 16.10471 ; the females' std. deviation is 12.73372. The males' std. error mean is 2.54638 while the females' std. error is 2.77873 . The males' means of the experimental class in the creative thinking ability posttest is 52.5517, which is lower than females' means of the experimental class: 60.7576. The males' std. deviation is 17.14973 and the females' std. deviation is 10.05619. The 
males' std. error mean is 3.18463 and the females' std. error is 1.75056. Through the analysis of the group statistics in posttest, we

In summary, the Internet provides a way for students to effectively learn; at the same time, creative thinking ability can be cultivated through English learning, and the acquisition of creative thinking ability should be an important part of English learning, so English teachers should put emphasis on nurturing students' creative thinking by making good use of the Internet and the web resources.

\section{Conclusion}

Major findings and discussions of the current study are summarized; the implications for the study are made and limitations of the study are presented in this section.

The present study provides answers to the two research questions put forward earlier. According to the results we got from this research, college students have the tendency to be more creative under web-based English teaching circumstances.

There are no significant differences between pretest and posttest of creative thinking ability in the control class and in the experimental class. However, when analyzing other data of pretest and posttest in two classes, can also find that males' creative thinking ability is lower than females'.

we can find that college students' creative thinking ability under network-based English teaching circumstances is slightly higher than under traditional teaching circumstances. College students' creative thinking ability under network-based English teaching circumstances makes some more progress than under traditional teaching circumstances. Thus, network-based English teaching produces effects on improving college students' creative thinking ability. Besides, although there are no significant differences between the variables of pretest and posttest of creative attitude in control class, there are significant differences between pretest and posttest in experimental class. Differences based on sex in creative thinking ability and creative attitude do exist. Females' creative thinking ability and creative attitude is relatively higher than males'.

\section{References}

[1] Albrecht, The Creative Corporation [M]. Homewood, IL: Jones-Itwin. 1987.96.

[2] Amabile, T. M, The Social Psychology of Creativity [M]. New York: Springer-Verlag. 1983. 